\title{
Plan de recuperación del patrimonio documental de la comunidad judía de Chile ${ }^{1}$
}

Recovery plan for the documentary heritage of the Jewish community in Chile

Judith Riquelme Ríos ${ }^{2}$

Universidad Tecnológica Metropolitana (UTEM)

riquelme.judith@gmail.com

\section{RESUMEN}

Este artículo revisa el concepto de patrimonio documental vinculado a la Comunidad Judía de Chile. Presenta los fundamentos que permitieron impulsar la creación del Archivo de Judaísmo Chileno (AJCH), cuya misión es recuperar, conservar y preservar los documentos generados por la comunidad. El plan de recuperación del patrimonio comunitario se circunscribe a otras acciones realizadas por el Centro de Estudios Judaicos de la Universidad de Chile que buscan posibilitar nuevos estudios multidisciplinarios en torno a los objetos de información generados por este grupo de inmigrantes.

PALABRAS CLAVE: Patrimonio cultural - memoria - archivos - Comunidad Judía

\begin{abstract}
This article reviews the concept of documentary heritage linked to the Jewish Community of Chile. Presents the fundamentals that drive the creation allowed Chilean Archive Judaism (AJCH), whose mission is to restore, conserve and preserve the documents generated by the community.

The recovery plan is limited to community heritage other actions taken by the Center for Jewish Studies seeking to enable new multidisciplinary studies information objects generated by this group of immigrants
\end{abstract}

KEYWORDS: Heritage - memory - archives - Jewish Community

\footnotetext{
${ }^{1}$ Publicado en Cuadernos Judaicos-No $30(2013)$

${ }^{2}$ Judith Riquelme es la Directora del Archivo Histórico del JUdaismo Chileno.
} 
Patrimonio y Archivo

En la sociedad actual, el bien más preciado y estratégico es la información. Para el sociólogo Mattelart (2002) la información es un bien público fundamental para el desarrollo económico y la generación de nuevo conocimiento. En ese sentido el rol de los organismos culturales que custodian la información requiere de políticas que favorezcan el acceso igualitario al patrimonio cultural y su preservación.

El Centro de Estudios Judaicos, unidad académica de la Universidad de Chile cuya misión es "Fortalecer el conocimiento en pro de la transmisión y preservación de los valores históricos culturales del pueblo judio en el contexto de las diversas culturas a través de la docencia, extensión, e investigación ${ }^{3 "}$, se ha propuesto entre sus objetivos estratégicos "fortalecer los servicios de información y documentación sobre la cultura judaica"4 para dar cumplimiento a este objetivo mantiene una biblioteca especializada en cultura judía desde 1968. Esta unidad de información universitaria se encuentra abierta a todos quienes tengan interés en la temática judaica. Su colección bibliográfica sobrepasa los 9.036 volúmenes. El núcleo de su colección está formado por una gran variedad de libros, revistas y periódicos judíos. En ella se pueden encontrar materiales sobre inmigración judía a Chile, comunidades judías del mundo, filosofía, religión y textos sagrados, Holocausto, antisemitismo, identidad, costumbres y tradiciones judías, folclore judío, literatura judía; biografías, novelas, memorias, cuentos. La colección incluye materiales en hebreo, ídish, español, inglés, alemán, griego, latín, francés y otros idiomas.

Para potenciar los servicios de información y documentación sobre la cultura judaica, la Dirección del Centro, consciente de la importancia de la preservación de la memoria comunitaria y el patrimonio documental, impulsó a fines de 2008, la ambiciosa tarea de la formación de un Archivo especializado único en su tipo, el patrimonio documental contiene documentos antiguos, de alto valor histórico y cultural. Su acervo está integrado

\footnotetext{
${ }^{3}$ Centro de Estudios Judaicos http://www.estudiosjudaicos.cl/?q=node/10

${ }^{4}$ Ibíd.
} 
por archivos personales y familiares y por archivos de instituciones comunitarias, compuestos por manuscritos, libros de cuentas, libros antiguos, documentos, hojas sueltas, fotografías, negativos, material audiovisual y sonoro, recortes de prensa, tarjetas, afiches, folletos.

Esta iniciativa ha sido pionera en nuestro país y en la Universidad en particular.

\section{Patrimonio Cultural y Patrimonio Documental}

El concepto de patrimonio cultural comprende todos aquellos bienes expresiones y testimonios de la creación humana que brindan identidad a una nación.

Según la Convención para la Protección del Patrimonio Cultural "para existir cada persona necesita dar testimonio de su vida diaria, expresar su capacidad creativa y preservar los trazos de su historia. Esto solamente es logrado a través del patrimonio cultural" (UNESCO, 1972). El significado social del concepto de patrimonio cultural se mantiene en el espacio de una herencia común para toda la humanidad, por esa razón los gobiernos y sus pueblos tienen la obligación de preservarlo y custodiarlo responsablemente. El patrimonio cultural asienta el respeto a la diversidad, la tolerancia y la inclusión, así mismo enriquece a la sociedad otorgando un resplandor de esperanza enraizada en la historia.

En el documento, Declaración Universal sobre Diversidad Cultura se señala que:

"Toda creación tiene sus orígenes en las tradiciones culturales, pero se desarrolla plenamente en contacto con otras culturas. Ésta es la razón por la cual el patrimonio, en todas sus formas, debe ser preservado, realzado y transmitido a las generaciones futuras como testimonio de la experiencia y de las aspiraciones humanas, a fin de nutrir la creatividad en toda su diversidad e inspirar un verdadero diálogo entre las culturas" (UNESCO, 2002).

Agrupaciones relacionadas con el manejo del patrimonio cultural tangible han manifestado su preocupación por la fragmentación de la memoria del mundo, por 
ejemplo, la Federación Internacional de Asociaciones de Bibliotecarios en 2012, reconoce que mucho de los elementos del patrimonio cultural son únicos y su desaparición es una pérdida clara y un empobrecimiento irreversible para la sociedad y la humanidad en su conjunto. De igual modo el Consejo Internacional de Archivos (ICA), hace hincapié en el valor y riqueza ilimitada de los documentos de archivo y reflejan la producción de la actividad humana y componen el testimonio irremplazable de hechos pasados.

El patrimonio documental es parte del concepto de patrimonio cultural, el cual describe la vida de personas de tiempos pasados. Nos permite conocer sus actos, creencias y su cultura materializados en documentos. Está conformado por los archivos que se definen como conjunto de documentos de cualquier época, acumulados por una persona o institución pública o privada, en el transcurso de su vida o gestión.

Entendemos la trascendencia de los documentos, es decir, si bien en muchas ocasiones corresponden a la identidad social de un grupo, pueblo o nación pertenecen a la humanidad y no a un grupo en particular. Conscientes de la importancia de memoria colectiva es imprescindible que los todos los ciudadanos los conozcan, valoren y utilicen.

Los objetos culturales que forman el Patrimonio Tangible Mueble se constituye como parte fundamental del patrimonio de archivos, bibliotecas y museos. Por ende, conservar, preservar y difundir la información que contienen es obligación de quienes lo custodian.

El patrimonio documental incluye registros textuales y no textuales (manuscritos, fotografías, afiches, registros sonoros, audiovisuales) que a través de su estudio y difusión contribuyen al conocimiento de un grupo humano y de su época permitiéndonos crear vínculos entre el pasado y el presente.

Las herramientas para recoger, ordenar y clasificar y analizar información histórica dependen del objeto de estudio.

La utilización de fuentes primarias es de vital importancia no solo para investigadores sino también para profesores y estudiantes en general. 


\section{Archivos y acceso a la información}

El patrimonio documental es entendido como tangible o bien mueble, es decir, comprende todo aquello que es posible de ser trasladado, lo cual nos habla de su fragilidad y vulnerabilidad.

Universalmente el concepto de archivo se entiende como toda forma que puede asumir un documento independiente de su soporte.

Dado el valor social que resguardan los documentos, los archivos han sido desde tiempos antiguos asociados al poder y por lo mismo muchas veces han sido al igual que las bibliotecas objetos de destrucción.

El desarrollo de los archivos y la valorización de los documentos como elementos probatorios se visualiza en la historia humana desde las tablillas sumerias que registraban información agrícola contable, hasta nuestro días en que la sociedad más participativa demanda conocer información administrativa del Estado.

El acceso a los archivos ha ido cambiando, en épocas antiguas, solo unos pocos vinculados al ejercicio del poder tenían la posibilidad de tener información, en el antiguo Egipto, Mesopotamia o China el acceso era para quienes detentaban el poder religioso. El progreso de la humanidad, sus leyes y el avance de los estudios históricos generó la apertura gradual de archivos que contribuyeron al esclarecimiento de situaciones que afectan los derechos de humanos. La destrucción y devastación de archivos, durante la Segunda Guerra era una consecuencia inevitable dado la situación. Pero al término de la Conflagración la incautación de los archivos alemanes por parte de las fuerzas armadas estadounidense contribuyó a conocer la responsabilidad de los Nazis en la Guerra (Duchein, 1983).

Solo después de la Segunda Guerra Mundial el acceso a la información fue explicitado en la Declaración de los Derechos Humanos, artículo 19 "Todo individuo tiene derecho a la libertad de opinión y de expresión; este derecho incluye el de no ser molestado a causa de sus opiniones, el de investigar y recibir informaciones y opiniones, y el de 
difundirlas, sin limitación de fronteras, por cualquier medio de expresión" Una excepción a esta norma es aquella información que afecta la vida privada de las personas. Como puede apreciarse los archivos han sido objetos de silencios y también de destrucción. Nuestro país no es ajeno a los problemas en materia de archivos, se han ido perdiendo gran cantidad de fuentes por la falta de preocupación y de una legislación archivística nacional adecuada. Pese a que la Constitución, en el artículo 19 inciso 10, contempla la protección e incremento del patrimonio cultural de la nación, y a que el Archivo Nacional tiene entre sus objetivos conservar, poner en valor y dar acceso al patrimonio documental en beneficio de la investigación y la memoria colectiva, mucho del patrimonio documental del país se ha perdido irremediablemente. En el caso del patrimonio documental de la Comunidad Judía del siglo XX, parte importante fue sacado del país y hoy se encuentra en el Archivo del Pueblo Judío de la Universidad Hebrea Jerusalén.

El subfondo archivístico dedicado a Chile contiene documentos de los años 1909-1974. Parte de las series documentales contienen información de organizaciones judías como la Comunidad Israelita y la Federación Sionista de Chile. Esta documentación incluyen documentos de fundación, actas y estatutos originales, actas de sesiones y documentos sobre actividades y protestas antinazis, correspondencia referente a refugiados de la Segunda Guerra Mundial, peticiones de datos sobre la inmigración de sobrevivientes y posibles indemnizaciones.

Si se profundiza en el fondo se puede encontrar material relativo a instituciones israelitas en diversas localidades del país, así como de otras organizaciones comunitarias, Vaad Hajinuj, Organizaciones femeninas, la Comunidad Sefaradita, instituciones culturales como la organización "Bnei Israel", el centro cultural "Mazse" de judíos de habla húngara, la organización de judíos de origen polaco, escuelas, movimientos juveniles, organizaciones de salud y bienestar social, así como diversas publicaciones locales.

Es necesario establecer vínculos de comunicación y colaboración con el Archivo Central de la Historia del Pueblo Judío para recuperar parte de la historia de la Comunidad Judía en Chile. Para construir la historia de una comunidad o nación, es fundamental 
resguardar la memoria y el patrimonio cultural con el fin de servir de base para futuros diálogos que reconozcan las diferencias entre las personas y promuevan la tolerancia.

\section{$1 \quad$ Primeros pasos}

Chile es un país de inmigrantes, formado por personas de distintas partes del mundo y de diferentes culturas. Destacados políticos como O’Higgins y Carrera quisieron incentivar la inmigración a nuestro país. Con todo, no fue hasta la promulgación de la Ley de InmigraciónSelectiva en 1845, que se concretó la llegada masiva de extranjeros al país. Esta política de Estado fue reforzada por Vicuña Mackenna y se estableció una categorización preferente de ingreso de los inmigrantes según su país de origen y según sus oficios.

Para el investigador Günter Böhm (1948) la presencia judía en Chile se encuentra documentada desde 1535 -acompañando a Almagro vino el converso Rodrigo de Orgoñez y junto al conquistador Pedro Valdivia llegó Diego García de Cáceres. Estudios recientes señalan que "el proceso migratorio de judios a Chile se puede situar en dos grandes períodos; uno, entre la conquista española y 1895; otro que comprende desde 1895 hasta 1950 aproximadamente”. (Matus, 2011)

El primer periodo migratorio fue estudiado en detalle por Günter Böhm (1948), quien además recopiló parte importante del patrimonio documental de los extranjeros de origen judío del siglo

XIX. Uno de los documentos más antiguo que recuperó está fechado en 1892 y se trata de un certificado de título, (Figura 1) firmado por el rector de la Universidad de Chile de ese entonces José Joaquín Aguirre. 


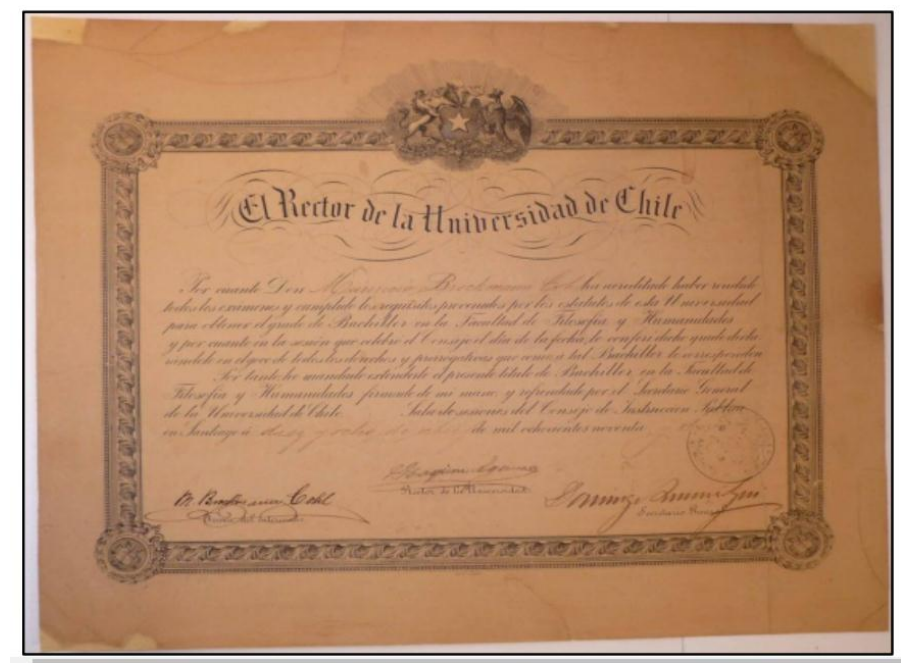

Figura 1. Diploma del Bachiller Mauricio Brockmann

Los primeros inmigrantes judíos no se consideraron así mismos como judíos, en algunos casos, se asimilaron a otras comunidades de inmigrantes formando parte de sus instituciones. Es lo ocurrido con la familia Goldenberg en Chillán, quienes se integraron a la comunidad Alemana y se asimilaron a la sociedad chilena local. Salomón Goldenberg figura como benefactor del Club Alemán 1856. El Archivo del CEJ posee documentos que dan cuenta de sus orígenes judíos, los cuales fueron sometidos a un proceso de conservación por el frágil estado en que se encontraban (Figura 2 y 3 ).
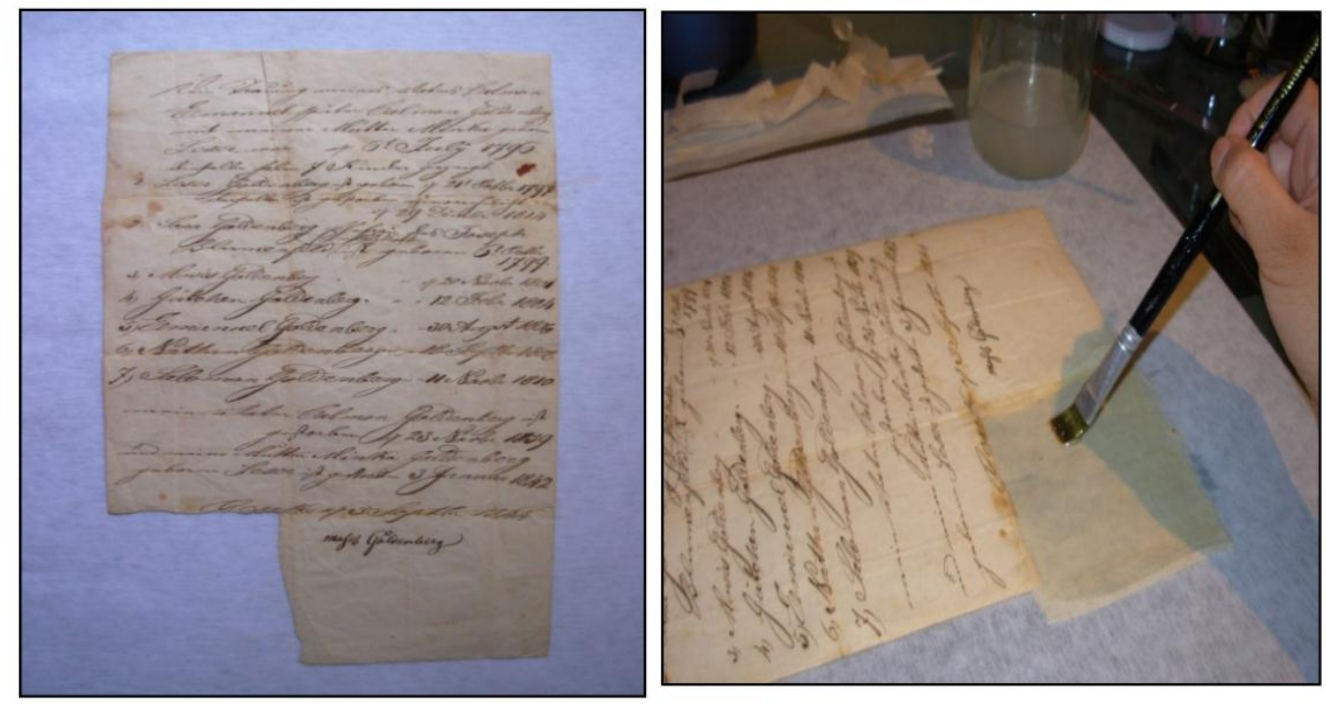

Figura 2 y 3. Carta de familia Goldenberg 
En el centro del país se observa la presencia de algunos inmigrantes judíos en la ciudad de Valparaíso. Familias provenientes de Francia, Alemania e Inglaterra se instalan en el puerto y forman parte de la sociedad de la época. Como señala Böhm en la iglesia de La Matriz encontramos documentos probatorios de la celebración del primer matrimonio judío celebrado en Chile en 1867.

En 1906, en Santiago, un pequeño grupo de inmigrantes judíos, se congregó, “durante el rosh hashana, se reunió por primera vez un grupo de judíos en la casa de mi padre, para celebrar el primer minian"” (Tapia Adler, A., Riquelme, J., 2013)

El censo de 1907 indicaba que en Temuco había 14 familias judías. Fue en esta ciudad donde se edificó la primera sinagoga del país.

Tres años más tarde el Presidente Manuel Montt firma los estatutos de la Unión Israelita de Chile. Posteriormente se fortalecen las comunidades en regiones: Comunidad Israelita Concepción y de Puerto Montt, se consolidan en 1930, la Comunidad de Los Ángeles en 1960 y la Comunidad Israelita de Iquique, en 1976.

En 2006 la Comunidad Judía de Chile cumplió cien años de vida organizada. Respecto al concepto sociológico de comunidad consideramos que "se entiende como el conjunto de interacciones, comportamientos humanos que tienen un sentido y expectativas entre sus miembros. No solo acciones, sino acciones basadas en esperanzas, valores y creencias y significados compartidos entre personas" (Bartle, 2013), esta conceptualización se condice con la noción de Comunidad del pueblo judío hasta nuestros días. Las personas

5 Rosh hashana: año nuevo judío

6 Minian: servicio religioso debe contar con mínimo de diez personas para celebrar ciertos rituales o preceptos. 
con orígenes judíos se estiman en $150 \mathrm{mil}^{7}$ la gran mayoría concentrados en Santiago. Sus comunidades surgen de inmigrantes provenientes de Alemania, España, Portugal, Polonia, Rusia, Italia, Grecia, Turquía, Austria. Según datos de la Comunidad Israelita de Santiago, actualmente cuentan con tres colegios judíos, grupos juveniles, grupos de mujeres, dos hogares de ancianos, una compañía judía de bomberos, una red de acción solidaria, un estadio, un policlínico público, seis sinagogas ortodoxas, cinco conservadoras y dos reformistas.

Consideramos que recopilar y preservar el patrimonio documental de los inmigrantes minoritarios, como la Comunidad Judía de Chile, es esencial para re-conocer nuestra identidad, alcanzar un desarrollo equilibrado como sociedad tolerante e inclusiva, sobre todo hoy que Chile acoge principalmente migrantes de países como Perú, Argentina, Colombia, Haití, quienes muchas veces son objetos de discriminación e intolerancia.

El rescate de la memoria de la Comunidad Judía a través de sus objetos, documentos, fotografías nos entregará un referente sobre su inmigración, su memoria colectiva. Cabe la posibilidad de recopilar documentación que muestre sus acciones, sus costumbres y tradiciones; nacimientos, matrimonios, defunciones, cartas personales, nóminas escolares, actas de Instituciones comunitarias.

\section{El Archivo de Judaísmo Chileno}

Muchas veces hemos tenido entre nuestras manos documentos que relatan información más o menos importante, dependiendo del lector. A partir de su lectura hemos reconstruido rostros, escuchado a quienes los escribieron, hemos percibido olores y perfumes y quizás hemos encontrado parte de nuestras vidas. Es la recuperación de la memoria el ejercicio necesario de la vida de todo grupo humano.

7 Zaliasnik, (23 de 12 de 2012). Los judíos residentes en Chile aceptan el Estado palestino. Estocolmo. 
Señalamos, que el objetivo de este proyecto en desarrollo, es reunir y conservar la documentación generada por personas de origen judío y por instituciones de la comunidad judía, que dan cuenta de los aportes de este grupo a la sociedad chilena.

La idea de crear un Fondo Archivístico, nace afines de 2008 cuando el Centro de Estudios Judaicos recibe la donación de la documentación acopiada por el profesor Günter Böhm durante su vida como investigador. La documentación estaba compuesta por fotografías, cartas, libros, álbumes, recortes de prensa, tarjetas. Parte de este material corresponde al siglo XIX-1845 en adelante- otra parte al siglo XX.

En una primera etapa de este proyecto se decidió restaurar los documentos y fotografías más dañadas de este modo se buscó asegurar su conservación. (Figura 4)

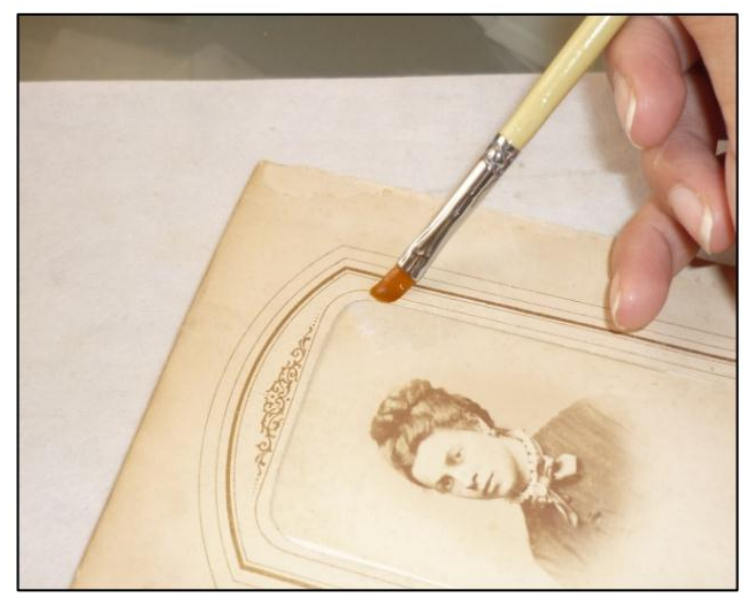

Figura 4. Álbum Fotográfico.

Posteriormente se revisó, ordenó, clasificó todo el sub fondo Günter Böhm. Alcanzando, solo este subfondo, un acervo documental de 185 series documentales (45 metros lineales). La lengua predominante es el español, sin embargo encontramos algunas cartas familiares en alemán idish y hebreo. Una vez finiquitada la organización del subfondo se procedió a describir las series documentales en una base de datos automatizada bajo estándares archivísticos internaciones, - norma de descripción general ISAD G, IDSIAH. 
Cada unidad documental del archivo ha sido digitalizada en formatos de conservación (TIFF) y publicación (JPJ Y PDF), el objetivo de esta tarea es ampliar la cobertura de acceso a la documentación a través de internet para toda la comunidad nacional e internacional. Inicialmente se seleccionaron para digitalización los manuscritos del siglo XIX. Se decidió agregar un sello de agua a las imágenes para reconocer su pertenencia.

Durante 2013 se ha trabajado en la implementación de la plataforma tecnológica incluido el modelamiento de datos y el diseño de las interfaces de acceso y consulta. El software escogido fue el desarrollado por Consejo Internacional de Archivos, ATOM.

En paralelo se ha establecido alianzas con la Fundación Memoria Viva, institución que se dedica a reunir testimonios y documentos de personas afectadas por los acontecimientos generados a partir de la Segunda Guerra Mundial en Chile. La Fundación ha entregado al Archivo el subfondo audiovisual de memoria oral, "Voces de la Shoá", este fondo recoge información de personas víctimas de persecución y discriminación por su condición de judíos durante la primera mitad del siglo XX, las entrevistas filmadas en alta resolución a sobreviviente judíos del Holocausto que llegaron a radicarse a Chile.

Además de las tareas mencionadas, hemos recibido donaciones documentales en soporte papel y digital de las Familias familias Bogolasky Sack, Stekel, Donnebaum, Kaplan, Sharim, Horwitz, Simonosohn-Hammerchlag, Bronstein-Weinstein, Moreno Israel, Quiroga Doudtchitzky, (Figura 5) Sra. Edith Frank, familias Benadava, Tapia Adler y de instituciones comunitarias como la Quinta Compañía de Bomberos de Ñuñoa Bomba Israel. (Figura 6)

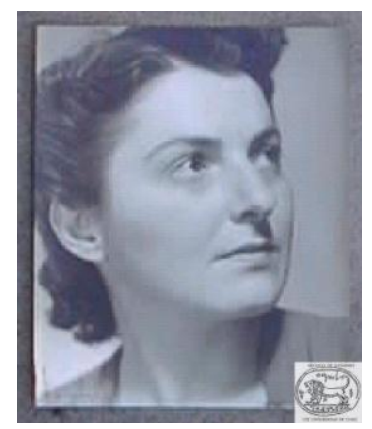


Figura 5 Dinora Doudtchitzky

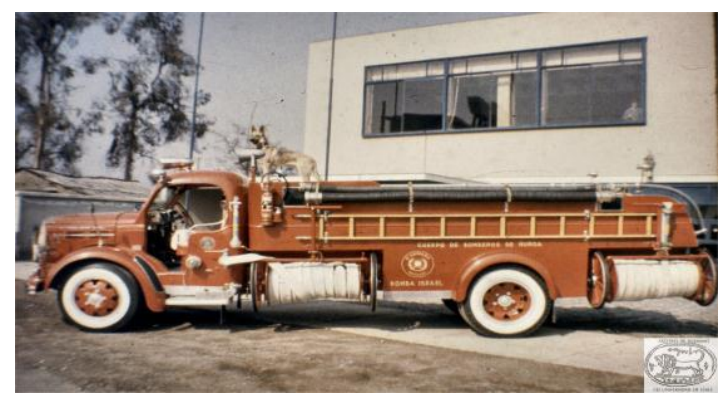

Figura 6. Carro Bomba Israel y el perro Quinta.

Se ha recopilado material de la Comunidad Judía de La Serena, Comunidad Sefaradí de Santiago, del Estadio Israelita Macabi y dos fotografías de Andacollo.

Entre las próximas metas del Archivo de Judaísmo Chileno, esta determinar nuevas existencias de objetos de información que conformen el patrimonio cultural en la Comunidad Judía, para esto nos hemos planteado desarrollar en un catastro del patrimonio documental judío. Hasta ahora el material recopilado ha ido ingresando por donación, recolección.

La documentación que conserva el Archivo de Judaísmo Chileno (AJCH) se sitúa cronológicamente entre 1845 y 2013, a pesar de sus dimensiones modestas, su valor radica en que resguarda material inédito, y único. Esperamos que esta iniciativa favorezca la discusión en torno al patrimonio documental de la comunidad judía y su aporte a nuestro país. Destacan las fuentes primarias para la investigación histórica y social de este grupo. Aún falta mucho por hacer, no obstante los logros son importantes para un archivo como memoria documental de un grupo, muestra los usos y costumbres de una comunidad y su desarrollo a través del tiempo, también hechos que con el tiempo se convirtieron en históricos.

\section{Bibliografía}

Bartle, P. (2013). What is comunity. Recuperado el 7 de septiembre de 2013, de http://edadm821.files.wordpress.com/2010/11/what-is-community.pdf 
Bohm, G. (1948). Los judíos en Chile durante la Colonia. Santiago: El esfuerzo.

Constitución Política de Chile. Recuperado 22 de septiembre de 2013, de http://www.camara.cl/camara/media/docs/constitucion_politica_2009.pdf

Declaración Universal de los Derechos Humanos. Recuperado 22 de septiembre de 2013, de http://www.un.org/es/documents/udhr/

Duchein. M. (1983). Los obstáculos que se oponen al acceso, a la utilización y a la transferencia de información conservada en los archivos. Recuperado 22 de noviembre de 2013, de http://unesdoc.unesco.org/images/0005/000576/057672so.pdf

Mattelat, A. (2002). Historia de la sociedad de la información. Barcelona: Paidós, ISBN: 8449311918

Matus, M. (2011). El viaje inmigratorio de las familias judías a Chile en el siglo XX. Cuadernos Judaicos, 205-221.

Programa de las Naciones Unidas para el Desarrollo (2006). Desarrollo humano en Chile: las nuevas tecnologías ¿un salto al futuro? Santiago: Mundi-Prensa, ISBN: 956 2790045

Programa de las Naciones Unidas para el Desarrollo (2010). Informe sobre el desarrollo humano 2010: la verdadera riqueza de las naciones: caminos al desarrollo humano. Madrid: Mundi- Prensa, ISBN: 978848476 4038.Recuperado 21 de noviembre de 2013, de http://hdr.undp.org/es/informes/mundial/idh 2010

Querol, M. (2010). Manual de gestión del patrimonio cultural. Madrid: Akal.

Stein, S. (18 de 09 de 2013). De la memoria suelta a la memoria emblemática. Obtenido de http://www.lapetus.uchile.cl/lapetus/archivos/1302552396stern.pdf

Tapia Adler, A. (2011). Costumbres y tradiciones judías. Santiago: Lom.

Tapia Adler, A., Riquelme, J., (2013) Entrevista a hija de José Robinovich. Manuscrito no publicado.

Taylor, D. (2003). The archive and the repertoire: performing cultural memory in the Americas. London: Duke University.

UNESCO. (1972). Convención sobre la protección del patrimonio mundial, cultural y natural.

UNESCO. (2002). Declaración universal sobre la diversidad cultural. Recuperado el 16 de septiembre de 2013, de http://unesdoc.unesco.org/images/0012/001271/127162s.pdf 
Vicuña Mackenna, B. (1865). Bases del informe presentado al Supremo Gobierno sobre la inmigración extranjera. Santiago: Imprenta Nacional. Recuperado el 16 de septiembre de 2013, de http://www.libros.uchile.cl/index.php/sisib/catalog/book/77

Zaliasnik, G. (2012). Los judíos residentes en Chile aceptan el Estado palestino. Estocolmo. Recuperado el 18 de septiembre de 2013, de http://estocolmo.se/noticias/?id=364 